\title{
EFFECT OF AIR-BORNE PARTICLE ABRASION/SINTERING SEQUENCE ON THE FLEXURAL STRENGTH OF ZIRCONIA. (AN IN VITRO STUDY)
}

\author{
Amr A.E. El-kashlan ${ }^{1 * B D s, ~ I h a b ~ A . ~ H a m m a d ~}{ }^{2} D S c$, Naguib A.N. El-Fawal ${ }^{3} P h D$.
}

\begin{abstract}
INTRODUCTION: Zirconia represents a valuable material that combines both color acceptance and ability to withstand high loads. It had been reported that sintering of Zirconia followed by air-borne particle abrasion affect its strength. The effect of air-borne particle abrasion/sintering sequence on shear bond strength of resin cements to Zirconia was found non-significant; however the effect of sequence on the flexural strength has not been reported. The Ivoclare Vivadent manufacturer recommendation is to sinter the Zirconia before subjecting it to any air-borne particle abrasion.

AIM OF THE STUDY: to evaluate the effect of air-borne particle abrasion/sintering sequence on the flexural strength of Zirconia.

MATERIALS AND METHOD: forty bars of dimensions $(26 \times 6 \times 1.5$ millimeter) were fabricated from IPS e-max zircad. The total number of specimens was divided into two equal groups (A and B). The specimens of group A (AS) were subjected to air-borne particle abrasion followed by sintering. However specimens of group B (SA) were sintered before air-borne particle abrasion. Specimens of each group were subjected to XRay Diffraction to show monoclinic-tetragonal phases percentage. Three-point loading was applied to all specimens to measure the flexural strength using a Universal Testing Machine.

RESULTS: At statistically significant level $\mathrm{p} \leq 0.05$. Group SA has showed significantly higher flexural strength compared to group AS. Airborne particle abraded surface of group SA showed the highest amount of monoclinic phase crystals after X-Ray Diffraction analysis.

CONCLUSIONS: Air-borne particle abrasion/sintering sequence affects flexural strength of Zirconia. Air-borne particle abrasion surface treatment induces tetragonal to monoclinic phase transformation in fully sintered Zirconia.

KEY WORDS: Sequence - Flexural strength - Pre-sintered - Zirconia - Air-borne particle abrasion.

RUNNING TITLE: Air-borne particle abrasion/Sintering sequence of Zirconia.
\end{abstract}

1. Master student in Fixed Prosthodontics at Faculty of Dentistry, Alexandria University, Alexandria, Egypt.

2. Professor of Fixed Prosthodontics, Department of Conservative Dentistry, Faculty of Dentistry, Alexandria University, Alexandria, Egypt.

3. Lecturer of Fixed Prosthodontics, Department of Conservative Dentistry, Faculty of Dentistry, Alexandria University, Alexandria, Egypt.

*Corresponding author:

E-mail: amr.alaa@pua.edu.eg

\section{INTRODUCTION}

All-ceramic restorations are now widely used in clinical practice for esthetic demand (1). Zirconia has proved superior mechanical properties which made it a reliable alternative to porcelain fused-to-metal (PFM) restoration, in addition to its biocompatibility and tooth-like color (2).

Zirconium oxide monoclinic and tetragonal allotropes have a transformation toughening phenomenon. Pure Zirconia exists as a monoclinic crystal structure at room temperature and transforms to tetragonal structure when sintering at $1173{ }^{\circ} \mathrm{C}$. For dental applications, Zirconia can be stabilized in tetragonal phase by the addition of 3mol\% yttrium oxide, resulting in Yttria-stabilized

Tetragonal Zirconia Polycrystalline (Y-TZP), which is metastable in its tetragonal crystalline at room temperature $(3,4)$. Improved mechanical properties of Zirconia are related to its transformation from tetragonal phase to monoclinic phase under externally applied compressive stresses. This transformation is accompanied by a $3 \%$ to $5 \%$ volume expansion that causes resistance to crack propagation, or in other words acts as crack stopper $(5,6)$.

Any of the in-lab or in-office procedures may be a contributing factor affecting the strength of Zirconia. During processing of a fixed dental prostheses, Zirconia may undergo air-borne particle abrasion surface treatment, or one of the other options of surface treatment, including diamond burs abrasion, silicoating, selective infiltration etching, and LASER (Light Amplification by Stimulated Emission of Radiation).

Studies have shown that surface treatment can accelerate tetragonal-to-monoclinic $(\mathrm{t} \rightarrow \mathrm{m})$ phase transformation associated with microscopic cracks $(7,8)$. Previous researches have suggested that air-borne particle abrasion before sintering is a useful method for significantly increasing the surface roughness of Zirconia. The sintering process is considered to reverse the transformation caused by air-borne particle abrasion. This reverse action caused acceleration of monoclinic-to-tetragonal $(\mathrm{m} \rightarrow \mathrm{t})(7,9)$.

The flexural strength represents the highest stress experienced within the material at its moment of yield (10). 
Factors affecting flexural strength of Zirconia include; grain size, shape of the Zirconia particles, and its tetragonal-monoclinic phases transformation toughening phenomenon (1), sintering temperature (12), number and size of surface flaws and surface roughness (13). When a material is tested for flexural strength, the surface subjected to the load is under compressive stress while the other surface is under tensile stress.

Controversy exists regarding the relationship between flexural strength of Zirconia and air-borne particle abrasion/sintering sequence. Many manufacturers recommend sintering of Zirconia before air-borne particle abrasion surface treatment. However the effect of reversing this sequence on flexural strength of Zirconia has not been reported.

The Null hypothesis is that there is no difference in flexural strength of Zirconia in different air-borne particle abrasion/sintering sequence. This study was designed to evaluate the effect of air-borne particle abrasion/sintering sequence on Zirconia's flexural strength.

\section{MATERIALS AND METHOD}

In order to fabricate Zirconia specimens from (IPS e-max ZirCAD, MT, A2; Ivoclare.Vivadent. Germany. LOTW12559) using CAD CAM machine (KaVo Everest. Germany), “3dCAD”software was used to design a specimen with dimensions (26 millimeter in length $\times 6$ millimeter in width $\times 1.5$ millimeter in thickness). Then file was saved in the '.STL' format and sent to KaVo Everest computer, in which calculations for dimensions to compensate for shrinkage 18.8246 percentage of 'IPS emax ZirCAD' after sintering, and arrangement of the bars with connectors that keep it attached during machining, were performed using "KaVo Hyperdent" software for nesting installed by default. The information was then sent to "KaVo Everest engine control CAM2 version 9.6" for processing of milling task.

The 'IPS e-max ZirCAD' had been firmly fixed inside the machine attachment platform, while "milling pin ZS1 long" and "CAM2 milling pin ZS2" were loaded into the machine. Milling progress started by rough milling of the bar and completed by fine milling. Machined bars were detached with low speed motor straight hand piece. Forty bars were fabricated by CAD CAM machine.

All the bars were polished using 1200 grit water-proof silicone-carbide paper as shown in figure (1).

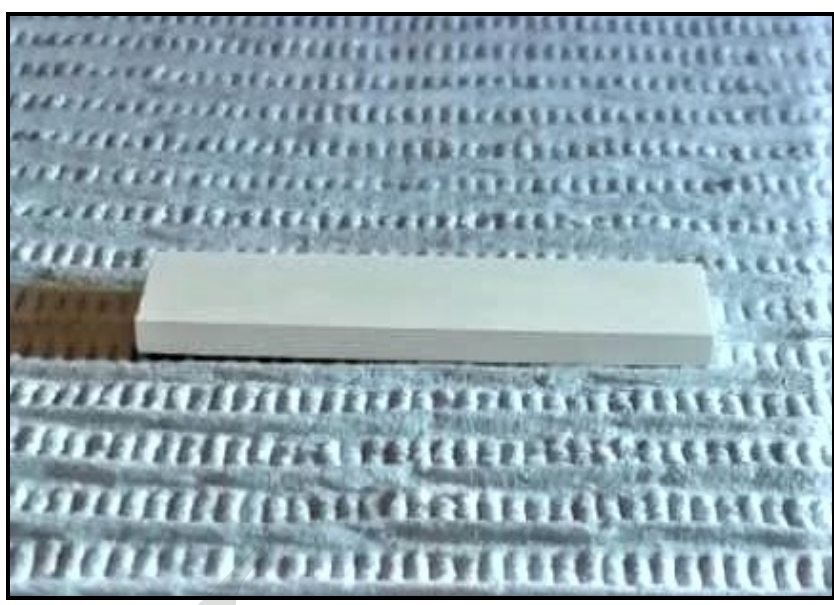

Figure (1): Showing a polished pre-sintered (Y-TZP) specimen.

The forty identical bar specimens were randomly divided into two equal groups, (group A) coded as 'AS' and (group B) coded as ' $\mathrm{SA}$ ' each consists of twenty specimens. Specimen dimensions were confirmed by digital caliber ('NEIKO' SAE-Metric Conversion New 01407A - China.). Special specimens holder had been designed and fabricated in metal. It was designed to hold specimens and meanwhile fix Air-borne particle abrasion (APA) nozzle as shown in figure (2),

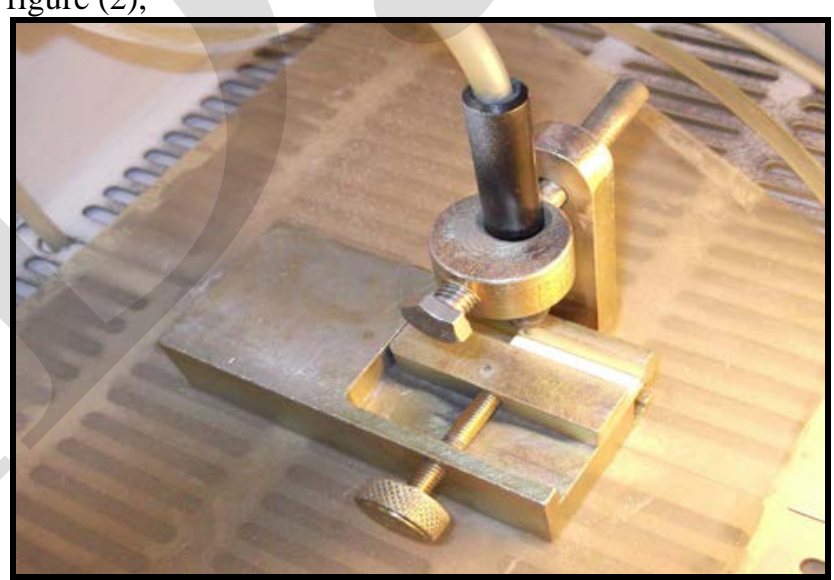

Figure (2): Pre-sintered (Y-TZP) specimen mounted on special holder inside chamber of air-borne particle abrasion device and nozzle fixed into a sliding arm.

with adjustable angle and distance from the surface of specimen to be treated. In addition to capability of sliding the nozzle at the adjusted angle and distance along the specimen. In group AS, pre-sintered (Y-TZP) specimens were first air-borne particle abraded using $120 \mu \mathrm{m}$ aluminum oxide (Al2O3) particles with 2 bar blasting pressure at a distance of 10 millimeter and 90 degrees incidence angle for $10 \mathrm{sec}$, using Air-borne particle abrasion device (model S 100/200/300, Silfradent S SOFIA-Forli - Italy). The specimen was sintered in Sintering machine (Ney Ceramfires, Dentsply. Switzerland.), at a heating speed of $5^{\circ} \mathrm{C} / \mathrm{min}$ to $1450^{\circ} \mathrm{C}$, and sustained that temperature for two hours, then it was kept to naturally cool to room temperature. In group SA, specimen was first sintered then air-borne particle abraded. 
All specimens for both groups were subjected to X-Ray Diffraction test by (X-Ray 7000 Shimadzu-Japan.) with Cupper Target, $40.0(\mathrm{kV})$ and $30.0(\mathrm{~mA})$ X-ray tube, as shown in figure (3).

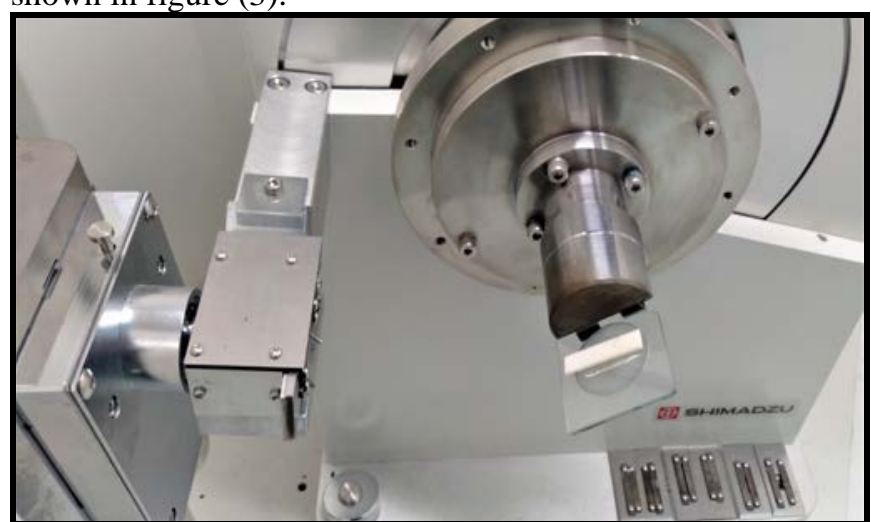

Figure (3): Showing (Y-TZP) bar specimen during X-Ray Diffraction test.

Specimen was continuously scanned at 5.0 - 80.0 (deg) scan range, 12.0 (deg/min) scan speed and 0.020(deg) sampling pitch.

All Data obtained by XRD for treated and untreated surfaces were then analyzed based on the COD-Inorganics reference database 2019 (Crystallography Open Database) using "Match!3” software program version 3.8.1.143 developed by 'Crystal Impact' company, Bonn, Germany. Each specimen for both groups was mounted on Universal Testing Machine (UTM) ("Autograph AG-IS Shimadzu”Japan.) to test flexural strength, where the untreated surface of each specimen is facing the compressing side. Force was applied to the middle of specimen at a crosshead speed of 1 millimeter/minute. Flexural strengths were calculated based on the following equation $(14,15)$ :

$$
\sigma=\frac{3 \times F \times L}{2 \times w \times h^{2}}
$$

Where:

$\sigma=$ Flexural strength $(\mathrm{MPa})$.

specimen width (mm).

$\mathrm{F}=$ Load at fracture $(\mathrm{N})$.

$\mathrm{h}=$ specimen

height (mm).

$\mathrm{L}=$ span between supports (mm).

Statistical analysis of data was done using software (SPSS), where the statistical significance was judged at $\mathrm{p} \leq$ 0.05 . Student t-test was used for comparison between the two studied groups according to tetragonal Zirconia phase (\%) and according to Flexural strength (Mpa). However, Mann Whitney test was used for comparison between the two groups according to baddeleyite (monoclinic Zirconia phase) (\%).

\section{RESULTS}

In this study, data results representing tetragonal and monoclinic phases distribution and percentage of each of Air-borne particle abraded surfaces and Untreated Zirconia surfaces for both Group AS and SA specimens, were all collected for statistical analysis.

Statistical analysis presented in table (1) and figure (4) showed significantly higher tetragonal Zirconia phase at both Air-borne particle abraded surface and Untreated Zirconia surface of Group AS with Probability of error (P) $<0.001$. While Baddeleyite (monoclinic Zirconia phase) (\%) was significantly higher at both Air-borne particle abraded surface and Untreated Zirconia surface of Group SA with probability of error $<0.001$.

After mounting of the specimens corresponding each studied group on UTM and load was applied, maximum load at failure was recorded and Flexural strength was calculated. Data results representing Flexural strength of bars in two groups were collected to be statistically analyzed. Statistical analysis presented in table (2) showed significantly higher Flexural strength for Group SA with probability of error $<0.001$, as shown in figure (5).

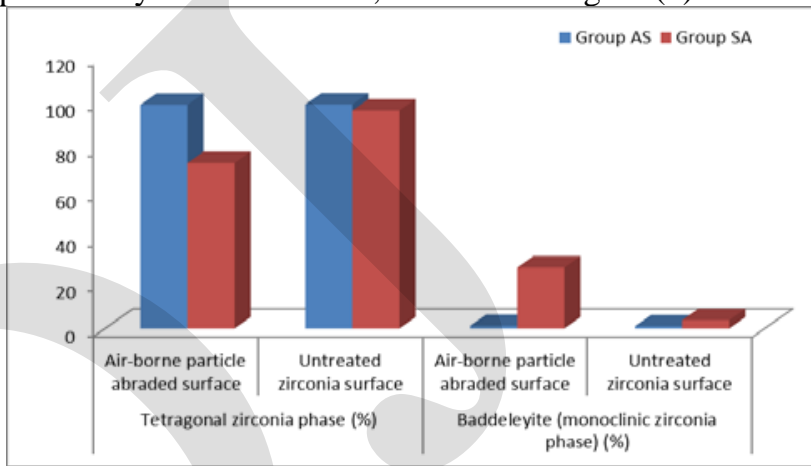

Figure (4): Showing comparison between the two groups according to tetragonal Zirconia phase (\%) and baddeleyite (monoclinic Zirconia phase) (\%).

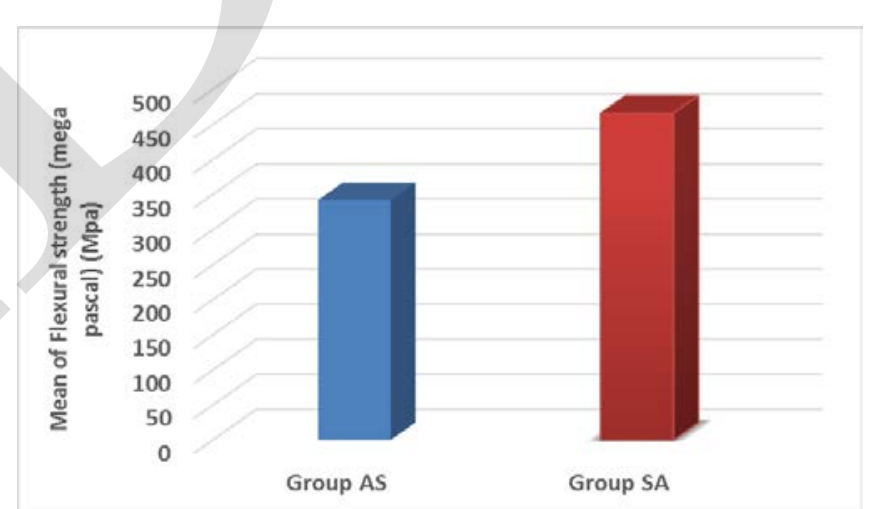

Figure (5): Showing comparison between the two groups according to Flexural strength (mega pascal) (Mpa). 
Table (1): Showing comparison between the two groups according to tetragonal Zirconia phase (\%) and baddeleyite (monoclinic Zirconia phase) (\%).

t: Student t-test. U: Mann Whitney test

$\mathrm{p}$ : p value for comparing between the two studied groups.

*: Statistically significant at $\mathrm{p} \leq 0.05$.

Group AS (Group A), Group SA (Group B).

Table (2): Showing comparison between the two groups according to 3 point loading.

\begin{tabular}{|c|c|c|c|c|}
\hline 3 point loading & $\begin{array}{c}\text { Group AS } \\
(\mathrm{n}=20)\end{array}$ & $\begin{array}{c}\text { Group SA } \\
(\mathrm{n}=20)\end{array}$ & $\begin{array}{c}\text { Test } \\
\text { of sig. }\end{array}$ & $\mathrm{p}$ \\
\hline $\begin{array}{l}\text { Flexural strength } \\
\text { (mega pascal) } \\
\text { (Mpa) }\end{array}$ & & & \multirow{4}{*}{$\mathrm{t}=4.089 *$} & \multirow{4}{*}{$<0.001 *$} \\
\hline Min. - Max. & $218.86-438.85$ & $270.80-733.33$ & & \\
\hline Mean \pm SD & $342.03 \pm 57.29$ & $465.93 \pm 122.81$ & & \\
\hline Median (IQR) & $\begin{array}{c}355.21 \\
(306.7-384.6\end{array}$ & $\begin{array}{c}443.06 \\
(376.6-556.5)\end{array}$ & & \\
\hline
\end{tabular}

t: Student t-test

$\mathrm{p}$ : p value for comparing between the two studied groups.

*: Statistically significant at $\mathrm{p} \leq 0.05$.

Group AS (Group A), Group SA (Group B).

\section{DISCUSSION}

In order to achieve a successful conservative dental approach, the need for combining between high strength material and adhesion is recommended as in cases of resinbonded Zirconia FPDs or cantilever restorations. These restorations do not depend on macro-mechanical principles for retention. Airborne particle abrasion is a method for creating roughness in surfaces of polycrystalline solids such as Zirconia. Controversy exists regarding influence of mechanical surface treatment protocol on phase transformation tendency in Zirconia and the potential for surface damage as micro-cracks. This conducted study compared airborne particle abrasion before and after sintering of Zirconia, regarding the percentage of surface tetragonal/monoclinic phases and flexural strengths.

In this study all specimens were fabricated by the CAD/CAM technology. A previous study had stated that Zirconia specimens were fabricated by cutting (oversized to compensate sintering shrinkage) using disks (16). Another study sliced Zirconia into bar specimens using a diamond-coated wheel (Isomet ${ }^{\circledR}$ 1000, Beuhler, Lake Buff, IL, USA) (17). Those researchers neglected CAD/CAM as a technology of producing Zirconia restoration in actual circumstances. Zirconia blocks manufactured in a standard process are subjected to complex network of events during CAD/CAM machining where the material may be vulnerable to residual stresses, subsurface damage or even chipping, as well as lateral and radial cracks $(18,19)$.

KaVo Everest. CAD CAM has been used to fabricate specimens of the current study, in which an open stl system provides easier procedure unrestricted by specific input source for a design creation, without the need for fabricating a special mold and scanning it.

Polishing was carried out for all specimens before grouping to standardize surface characteristics. İşerı et al 2010, polished Zirconia bars under water cooling using a grinder-polisher machine (Phoenix Beta Grinder/Polisher, Buehler, Germany). Ludovichetti et al 2019, manually polished Y-TZP disks using 600- and 1,200-grit sandpaper

\begin{tabular}{|c|c|c|c|c|c|}
\hline 2 & Surface & $\begin{array}{l}\text { Group AS } \\
(\mathrm{n}=20)\end{array}$ & $\begin{array}{l}\text { Group SA } \\
(\mathrm{n}=20)\end{array}$ & $\begin{array}{l}\text { Test of } \\
\text { sig. }\end{array}$ & $\mathrm{p}$ \\
\hline 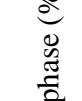 & $\begin{array}{l}\text { Air-borne } \\
\text { particle abraded } \\
\text { surface }\end{array}$ & & & \multirow{4}{*}{$\mathrm{t}=13.342 *$} & \multirow{4}{*}{$<0.001^{*}$} \\
\hline \multirow{7}{*}{ 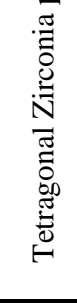 } & Min. - Max. & $97.90-99.90$ & $57.0-86.20$ & & \\
\hline & Mean \pm SD. & $98.82 \pm 0.62$ & $73.10 \pm 8.60$ & & \\
\hline & Median (IQR) & $\begin{array}{c}98.60 \\
(98.40-99.28) \\
\end{array}$ & $\begin{array}{c}73.55 \\
(68.65-77.30) \\
\end{array}$ & & \\
\hline & $\begin{array}{l}\text { Untreated } \\
\text { Zirconia surface }\end{array}$ & & & \multirow{4}{*}{$\mathrm{t}=4.987^{*}$} & \multirow{4}{*}{$<0.001^{*}$} \\
\hline & Min. - Max. & $98.10-99.90$ & $22.60-99.30$ & & \\
\hline & Mean \pm SD. & $98.97 \pm 0.45$ & $96.26 \pm 2.39$ & & \\
\hline & Median (IQR) & $\begin{array}{c}98.90 \\
(98.70-99.20)\end{array}$ & $\begin{array}{c}95.85 \\
(94.30-98.63) \\
\end{array}$ & & \\
\hline \multirow{8}{*}{ 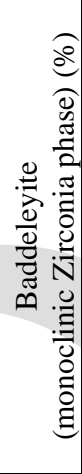 } & $\begin{array}{l}\text { Air-borne } \\
\text { particle abraded } \\
\text { surface }\end{array}$ & & & \multirow{4}{*}{$\mathrm{U}=0.0^{*}$} & \multirow{4}{*}{$<0.001^{*}$} \\
\hline & Min. - Max. & $0.10-2.10$ & $13.80-43.0$ & & \\
\hline & Mean \pm SD & $1.18 \pm 0.62$ & $26.90 \pm 8.60$ & & \\
\hline & Median (IQR) & $\begin{array}{c}1.40 \\
(0.73-1.60) \\
\end{array}$ & $\begin{array}{c}26.45 \\
(22.70-31.35) \\
\end{array}$ & & \\
\hline & $\begin{array}{l}\text { Untreated } \\
\text { Zirconia surface }\end{array}$ & & & \multirow{4}{*}{$\mathrm{U}=55.50^{*}$} & \multirow{4}{*}{$<0.001^{*}$} \\
\hline & Min. - Max. & $0.10-1.90$ & $0.70-7.40$ & & \\
\hline & Mean \pm SD. & $1.03 \pm 0.45$ & $3.75 \pm 2.39$ & & \\
\hline & Median (IQR) & $\begin{array}{c}1.10 \\
(0.80-1.30)\end{array}$ & $\begin{array}{c}4.15 \\
(1.38-5.70)\end{array}$ & & \\
\hline
\end{tabular}

(20). The purpose of standardized polishing procedure was to remove external irregular scratches in all fabricated bars for standardizing variables before starting surface treatments and to round the chipped corners of the specimens symmetrically (16).

Variables associated with airborne particle abrasion surface treatment such as, distance between the source of air-borne particle abrasion and surface to be treated as well as angle of applying air-borne particle abrasion might lead to different results (21). These variables are difficult to be controlled in freehand even by trained operator. It was essential for the current study to design and create a suitable special holder devise, that can control airborne particle abrasion procedure throughout the work.

Bar shape specimen possess more sharp angles liable to stress concentration representing worst situation where a Zirconia specimen is subjected to load, compared with a disk geometrical shape. In a study done to evaluate different test methods for mechanical properties of Monolithic Zirconia, flexural strength measured using the 3-point load test method on bars showed lower values compared to that measured with biaxial flexural strength on disks (22).

Stress trigger transformation toughening mechanism in $\mathrm{Y}$ TZP ceramics, where $(\mathrm{t})$ to $(\mathrm{m})$-phase transformation accompanied with local volumetric expansion (approximately 3-5\%) induces compression, that could prevent initiation of crack or act around an existing defect or crack tip against propagation. This has been extensively stated in literature (23-26). In the current study, XRD analysis results showed higher percentage of $(\mathrm{m})$ phase appeared at air-borne particle abraded surface of (SA) Group in comparison to untreated surfaces of Zirconia 
specimens. This means that air-borne particle abrasion surface treatment was capable of inducing phase transformation $(\mathrm{t} \rightarrow \mathrm{m})$ in fully sintered Y-TZP, and this is in agreement with De Kler et al (27). However, specimens that were subjected to heat treatment after air-borne particle abrasion (AS group) showed minimal (m) phase in contrast with (SA) group. This minimal (m)phase transformation is explained by the influence of sintering temperature that exceed the (m)phase occurrence range according to Pilathadka et al (28).

In work done by Juntavee \& Attashu (2018) (17), Zirconia bar specimens were sintered at different temperatures and holding times, then measured phase composition of Zirconia using X-ray diffraction machine (XRD, PANalytical, Empyrean, Almelo, Netherlands). Specimens were scanned with copper k-alpha $(\mathrm{Cu} \mathrm{K \alpha})$ radiation and $2 \theta$ degrees of ( $20-40^{\circ}$ range) with $0.02^{\circ}$ step size every 2 seconds' interval. Phases were analyzed in comparison to the known standard database. Statistically significant level was set at $(\alpha=0.05)$. XRD patterns revealed that most of the crystal structures are t-phase with minor amount of mphase in every group, where all groups hadn't been subjected to any airborne particle abrasion protocol. These results were in agreement with XRD for both treated and untreated surfaces of (AS)group specimens in the current study which were not subjected to any surface treatment after the sintering. This explains the slight conflict with $\mathrm{XRD}$ results of higher $\mathrm{m}$-phase(\%) shown in airborne particle abraded surface of (SA)group where it had been performed following the sintering process.

In the current study (SA)group failed under higher load ranges than (AS)group, that might be explained by the higher (m)phase \% at (SA)Group which acted as crack stopper $(5,6)$. Another explanation for these results based on Flury et al. (2012) who stated that "higher roughness produces lower mechanical properties of ceramics” (29). Another study has already showed that air-borne particle abrasion before sintering of Zirconia could produce higher surface roughness than after sintering (30).

Dilemma of creating or not creating roughness at surfaces of Zirconia restoration could be discussed from several aspects, since it was stated that roughness is beneficial for micromechanical retention meanwhile it decreases strength of material. Thus surface treatment must be a limited process that follows specific protocol based on certain criteria.

\section{CONCLUSIONS}

The following could be concluded within limitations of the current study:

- Air-borne particle abrasion surface treatment is capable of causing tetragonal to monoclinic phase transformation at Y-TZP surface when it is done after sintering.

- Air-borne particle abrasion/sintering sequence affects both the mechanical properties and crystal phase composition of Zirconia.

- Sintering of Zirconia then air-borne particle abrasion is associated with higher flexural strength compared to other reversed sequence provided that air-borne particle abrasion parameters are standardized. This could be due to the higher (m)phase \% at (SA)Group which acted as crack stopper.

\section{Conflict of interest}

The authors declare that they have no conflicts of interest.

\section{REFERENCES}

1. Hata U, Kawauchi D, Yamamura O, Fujii S. Chromatic Study of All ceramic Restorations: Relative Translucency of 9 All-ceramic Core Materials. Prosthodont Res Pract. 2008;7:153-5.

2. Nordahl N, Vult von Steyern P, Larsson C. Fracture strength of ceramic monolithic crown systems of different thickness. J Oral Sci. 2015;57:255-61.

3. Richerson DW. Modern ceramic engineering: properties, processing, and use in design. New York: Marcel Dekker; 1992. p.756-62.

4. Christel P, Meunier A, Heller M, Torre JP, Peille CN. Mechanical properties and short-term in vivo evaluation of yttrium-oxide-partially stabilized Zirconia. J Biomed Mater Res. 1989;23:45-61.

5. Subbarao EC. Advances in ceramics. Vol 3.Westerville $\mathrm{OH}$ : American Ceramics Society Inc; 1981. p.1-24.

6. Ban S. Reliability and properties of core materials for all ceramic dental restorations. Jpn Dent Sci Rev. 2006;44:3-21.

7. He M, Zhang Z, Zheng D, Ding N, Liu Y. Effect of sandblasting on surface roughness of Zirconia-based ceramics and shear bond strength of veneering porcelain. Dent Mater J. 2014;33:778-85.

8. Saito A, Komine F, Blatz MB, Matsumura H. A comparison of bond strength of layered veneering porcelains to Zirconia and metal. J Prosthet Dent. 2010;104:247-57.

9. Moon JE, Kim SH, Lee JB, Ha SR, Choi YS. The effect of preparation order on the crystal structure of yttria-stabilized tetragonal Zirconia polycrystal and the shear bond strength of dental resin cements. Dent Mater. 2011;27:651-63.

10. Ashby MF. Materials selection in Mechanical Design. Burlington, MA: Butterworth-Heinemann; 2011. p.40.

11. Guazzato $M$, Albakry $M$, Ringer $S$, Swain $M$. Strength, fracture toughness and microstructure of a selection of all-ceramic materials. Part II. Zirconiabased dental ceramics. Dent Mater. 2004;20:449-56.

12. Stawarczyk B, Özcan M, Hallmann L, Ender A, Mehl A, Hämmerlet C. The effect of Zirconia sintering temperature on flexural strength, grain size, and contrast ratio. Clin Oral Investig. 2012;17:269-74.

13. Çetinel F, Bauer W, Knitter R, Haußelt J. Factors affecting strength and shape retention of Zirconia micro bending bars during thermal debinding. Ceramics Int. 2011;37:2809-20.

14. ASTM C1161-02c(2008)e1, Standard Test Method for Flexural Strength of Advanced Ceramics at Ambient Temperature. Available at: https://webstore.ansi.org/standards/astm/astmc116102 c2008e1 
15. Calheiros FC, Pfeifer CS, Brandao LL, Agra CM, Ballester RY. Flexural properties of resin composites: influence of specimen dimensions and storage conditions. Dent Mater J. 2013;32:228-32.

16. İşerı U, Özkurt Z, Kazazoğlu E, Küçükoğlu D. Influence of grinding procedures on the flexural strength of Zirconia ceramics. Braz Dent J. 2010;21:528-32.

17. Juntavee N, Attashu S. Effect of different sintering process on flexural strength of translucency monolithic Zirconia. J Clin Exp Dent. 2018;10:e821-30.

18. Marshall DB, Evans AG, Khuri Yakub BT, Tien JW, Kino GS. The nature of machining damage in brittle materials. Proc R Soc Lond A Math Phys Sci. 1983;385:461-75.

19. Rekow D, Thompson VP. Near-surface damage-a persistent problem in crowns obtained by computeraided design and manufacturing. Proc Inst Mech Eng Part H. 2005;219:233-43.

20. Francesco Saverio L, Branco MS, Flávia ZT, Filipe de Oliveira AR, Renata GF. Garcia Fonseca R. Does the cleaning method after air abrasion with different particles affect the Zirconia bond strength? J Oral Science Rehabilitation. 2019;5:26-33.

21. Ho B, Tsoi J, Liu D, Lung C, Wong H, Matinlinna J. Effects of sandblasting distance and angles on resin cement bonding to Zirconia and titanium. Int J Adhes Adhes. 2015;62:25-31.

22. Schatz C, Strickstrock M, Roos M, Edelhoff D, Eichberger M, Zylla I, et al. Influence of Specimen Preparation and Test Methods on the Flexural Strength Results of Monolithic Zirconia Materials. Materials. 2016;9:180.
23. Gupta TK, Lange FF, Bechtold JH. Effect of stressinduced phase transformation on the properties of polycrystalline Zirconia containing metastable tetragonal phase. J Mat Sci. 1978;13:1464-70.

24. Hannink RHJ, Kelly PM, MuddleBC. Transformation toughening in Zirconia- containing ceramics. J Am Ceram Soc. 2000;83:461-87.

25. Pereira GK, Venturini AB, Silvestri T, Dapieve KS, Montagner AF, Soares FZ, et al. Low-temperature degradation of Y-TZP ceramics: a systematic review and meta-analysis. J Mech Behav Biomed Mater. 2015;55:151-63.

26. Hjerppe J, Narhi TO, Vallittu PK, Lassila LV. Surface roughness and the flexural bend strength of Zirconia after different surface treatments. J Prosthet Dent. 2016;116:577-83.

27. De Kler M, de Jager N, Meegdes M, van der Zel JM. Influence of thermal expansion mismatch and fatigue loading on phase changes in porcelain veneered $\mathrm{Y}$ TZP Zirconia discs. J Oral Rehabil. 2007;34:841-7.

28. Pilathadka S, Vahalová D, Vosáhlo T. The Zirconia: a new dental ceramic material. An overview. Prague Med Rep. 2007;108:5-12.

29. Flury S, Peutzfeldt A, Lussi A. Influence of surface roughness on mechanical properties of two CAD/CAM ceramic materials. Oper Dent. 2012;37:617-24.

30. Skienhe H, Habchi R, Ounsi HF, Ferrari M, Salameh Z. Structural and Morphological Evaluation of Presintered Zirconia following Different Surface Treatments. J Contemp Dent Pract. 2018;19:156-65. 